\title{
Efficacy and safety of intramuscular administration of allogeneic adipose tissue derived and expanded mesenchymal stromal cells in diabetic patients with critical limb ischemia with no possibility of revascularization: study protocol for a randomized controlled double-blind phase Il clinical trial (The NOMA Trial)
}

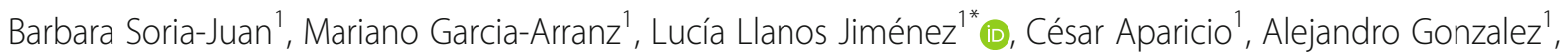
Ignacio Mahillo Fernandez', Luis Riera del Moral ${ }^{2}$, Lukasz Grochowicz ${ }^{3}$, Enrique J. Andreu ${ }^{3}$, Pedro Marin ${ }^{4}$, Gregorio Castellanos ${ }^{4}$, Jose Maria Moraleda ${ }^{4}$, Ana Maria García-Hernández ${ }^{4}$, Francisco S. Lozano ${ }^{5}$, Fermin Sanchez-Guijo ${ }^{5}$, Eva María Villarón ${ }^{5}$, Miriam Lopez Parra ${ }^{5}$, Rosa María Yañez ${ }^{6}$, Antonio de la Cuesta Diaz Juan Rigoberto Tejedo ${ }^{8}$, Francisco J. Bedoya ${ }^{8,9}$, Franz Martin $^{8}$, Manuel Miralles ${ }^{10}$, Lourdes del Rio Sola ${ }^{11}$, María Eugenia Fernández-Santos ${ }^{12}$, José Manuel Ligero ${ }^{12}$, Francisco Morant ${ }^{13}$, Luis Hernández-Blasco ${ }^{13}$, Etelvina Andreu ${ }^{13,14}$, Abdelkrim Hmadcha ${ }^{8,15,16}$, Damian Garcia-Olmo ${ }^{1}$ and Bernat Soria $8,13,14$

\begin{abstract}
Background: Chronic lower limb ischemia develops earlier and more frequently in patients with type 2 diabetes mellitus. Diabetes remains the main cause of lower-extremity non-traumatic amputations. Current medical treatment, based on antiplatelet therapy and statins, has demonstrated deficient improvement of the disease. In recent years, research has shown that it is possible to improve tissue perfusion through therapeutic angiogenesis. Both in animal models and humans, it has been shown that cell therapy can induce therapeutic angiogenesis, making mesenchymal stromal cell-based therapy one of the most promising therapeutic alternatives. The aim of this study is to evaluate the feasibility, safety, and efficacy of cell therapy based on mesenchymal stromal cells derived from adipose tissue intramuscular administration to patients with type 2 diabetes mellitus with critical limb ischemia and without possibility of revascularization.
\end{abstract}

\footnotetext{
* Correspondence: lucia.llanos@quironsalud.es

'Jimenez Diaz Foundation University Hospital, FJD Health Research Institute, IIS-FJD UAM, Madrid, Spain

Full list of author information is available at the end of the article
}

(c) The Author(s). 2021 Open Access This article is licensed under a Creative Commons Attribution 4.0 International License, which permits use, sharing, adaptation, distribution and reproduction in any medium or format, as long as you give appropriate credit to the original author(s) and the source, provide a link to the Creative Commons licence, and indicate if changes were made. The images or other third party material in this article are included in the article's Creative Commons licence, unless indicated otherwise in a credit line to the material. If material is not included in the article's Creative Commons licence and your intended use is not permitted by statutory regulation or exceeds the permitted use, you will need to obtain permission directly from the copyright holder. To view a copy of this licence, visit http://creativecommons.org/licenses/by/4.0/. The Creative Commons Public Domain Dedication waiver (http://creativecommons.org/publicdomain/zero/1.0/) applies to the data made available in this article, unless otherwise stated in a credit line to the data. 
Methods: A multicenter, randomized double-blind, placebo-controlled trial has been designed. Ninety eligible patients will be randomly assigned at a ratio 1:1:1 to one of the following: control group $(n=30)$, low-cell dose treatment group $(n=30)$, and high-cell dose treatment group $(n=30)$. Treatment will be administered in a singledose way and patients will be followed for 12 months. Primary outcome (safety) will be evaluated by measuring the rate of adverse events within the study period. Secondary outcomes (efficacy) will be measured by assessing clinical, analytical, and imaging-test parameters. Tertiary outcome (quality of life) will be evaluated with SF-12 and VascuQol-6 scales.

Discussion: Chronic lower limb ischemia has limited therapeutic options and constitutes a public health problem in both developed and underdeveloped countries. Given that the current treatment is not established in daily clinical practice, it is essential to provide evidence-based data that allow taking a step forward in its clinical development. Also, the multidisciplinary coordination exercise needed to develop this clinical trial protocol will undoubtfully be useful to conduct academic clinical trials in the field of cell therapy in the near future.

Trial registration: ClinicalTrials.gov NCT04466007. Registered on January 07, 2020. All items from the World Health Organization Trial Registration Data Set are included within the body of the protocol.

Keywords: Phase II clinical trial, Randomized, Adipose-derived mesenchymal stromal cells, Critical limb ischemia, Diabetes mellitus, Cell therapy, Advanced therapy medicinal products

\section{Background}

Critical lower limb ischemia (CLI) is characterized by chronic pain at rest, ulcers or gangrene attributable to a proven occlusive arterial disease [1]. The evolution of CLI, in the context of a generalized atherosclerotic disease, implies high morbidity and mortality. CLI develops earlier and with greater intensity in patients with diabetes mellitus, with complications that may result in the amputation of the limb and even death [2,3]. A public health goal of the standard of care is to decrease global cardiovascular risk through the control of risk factors by changes on lifestyle habits (quitting smoking, healthy diet, physical exercise) and pharmacological treatment (antiplatelet therapy, statins) [4]. However, there is insufficient evidence to show that this approach improves substantially the course of this disease [5]. Surgical or endovascular revascularization is often the treatment of choice, despite the fact that it is an invasive procedure that carries a high rate of complications. In addition, the health cost of this pathology is quite high. The treatment of the diabetic foot, and specifically critical limb ischemia, is the second most expensive complication in economic terms for the health system, just behind dialysis [6]. Efforts to prevent loss of the affected limb also include soft tissue debridement, minor amputations, and even skin grafts, all of which are costly procedures. In this context, given the high number of amputations that are still practiced annually worldwide, we are still in need of a cost-effective and easy-to-apply treatment [7]. Recently, research has shown that it is possible to improve tissue perfusion through therapeutic angiogenesis, making it one of the most promising strategies used to promote the proliferation of collateral vessels in ischemic tissues. In this sense, there are several methods to improve tissue perfusion, such as the administration of recombinant growth factors [8-11], or the constitutive expression of genes that encode for these factors through gene therapy [12]. Although both therapies have shown to promote angiogenesis in ischemic conditions in preclinical models [13], modest results were obtained when clinically applied [14-17]. In contrast, it has been shown both in animal models and in humans that cell therapy can induce therapeutic angiogenesis [18-20]. Cell-based therapies aiming to promote vascular regeneration gained interest with the discovery of a subpopulation of vasculogenic endothelial progenitor cells as reported by Asahara et al [17]. Human endothelial cell progenitors were isolated from peripheral blood by magnetic bead selection based on cell surface antigen expression. In animal models of ischemia, these cells have the ability to colonize the site of injury of ischemic tissue and secrete a number of vascular growth factors that can lead to clinically effective neovascularization [17]. It seems that these cells contribute to angiogenesis through the secretion of angiogenic cytokines and proteases such as matrix metalloproteases (MMPs), among others, helping the stability and growth of the endothelial and vascular network [21]. In 2002, the pioneering results of the TACT study (Therapeutic Angiogenesis using Cell Transplantation study) were published, consisting of a pilot uncontrolled safety study $(n=25)$ and a randomized controlled clinical trial to evaluate the use of mononuclear cells of bone marrow (BM) by intramuscular injection in 22 patients for treat peripheral arterial disease (PAD). Cell therapy with BM-derived mononuclear cells significantly improved ABI (difference 0.09 [95\% CI $0.06-0.11])$, transcutaneous oxygen pressure $(\mathrm{pTcO} 2)$, (13 [9-17]), rest pain $(-0.85[-1.6$ to -0.12$])$ and pain- 
free walking time $(1.2[0.7-1.7])$ in all treated patients [22]. Unfortunately, those with poorly controlled diabetes were excluded from the trial. As the prevalence of PAD increases in patients with type 2 diabetes mellitus (type 2 $\mathrm{DM})$ it is logical to assume that this population group is a potential candidate for cell therapy [22]. Since then, several studies have been carried out in which the transplantation of the mononuclear fraction of $\mathrm{BM}$ or peripheral blood has been shown to improve the endothelial function in the territories in which they were administered [23] and to improve ischemic pain and the healing of ulcers [24]. In a phase I/II, open-label, non-comparative clinical trial, safety and feasibility of treatment with autologous mesenchymal stromal cells (MSC) derived from BM and administered intra-arterially in patients with type $2 \mathrm{DM}$ and lower limb ischemia was studied. All of the participants ( $n$ $=20$ ) showed an increase in leg vascularization demonstrated by angiography and $100 \%$ of the ulcers healed. During the first year of follow-up, 7 minor amputations were performed, but no patient suffered a major amputation [25]. Cañizo et al. reported the first case of a patient with CLI treated with peripheral blood CD133+ cells. There were no major amputations and after 17 months of follow-up, patients experienced symptomatic and functional improvement. The group also observed the appearance of blood flow in the posterior tibial artery that was absent before the procedure [26]. The search for the most appropriate cell type for this pathology remains a challenge today [27], but the use of MSC is gaining prominence. The fact that these cells have trophic, immunomodulatory, and anti-inflammatory properties and liposuction is an easy and minimally invasive technique places them as suitable candidates for clinical use. The study that we propose here focuses on the development and optimization of an advanced therapy medicinal product (ATMP) based on adipose tissue-derived MSC (Ad-MSC) to be administered intramuscularly to patients with type $2 \mathrm{DM}$ and CLI within a multicenter randomized phase II clinical trial, favoring the translation of this cellular therapy to clinical practice. If proven safe and effective, an accessible, easy and minimally invasive treatment will be available for patients without any other option or that can even be associated with existing surgical treatments and improve their results.

The objectives of this study are the following:

1. To evaluate the safety and tolerability of the intramuscular administration of allogeneic Ad-MSC in patients with type $2 \mathrm{DM}$ with critical lower limb ischemia and no possibility of revascularization

2. To evaluate the preliminary efficacy of the treatment

3. To evaluate the quality of life of participants of the study after treatment administration

\section{Methods}

\section{Study design}

This is a study protocol of a multicenter, randomized, placebo-controlled, double-blinded, dose-finding, phase II clinical trial of three parallel groups to evaluate safety and efficacy of the intramuscular administration of allogeneic Ad-MSC in diabetic patients with CLI and without possibility of revascularization, over conventional treatment. The overall study design is reported according to the CONSORT statement and agrees with the SPIRIT 2013 checklist.

A total of 90 eligible patients will be recruited from ten academic hospitals in Spain (Jimenez Diaz Foundation University Hospital, La Paz University Hospital, Navarra University Clinic, Gregorio Marañón General University Hospital, Virgen de la Arrixaca University Clinical Hospital, Salamanca University Hospital, Victoria Eugenia-Cruz Roja Española Hospital, La Fe Clinical and Polytechnic University Hospital, Valladolid Clinical University Hospital and Alicante General University Hospital). Participants will be randomly assigned into control group, low-cell dose treatment group, or high-cell dose treatment group, at a ratio 1:1:1. The flowchart of the trial is presented in Fig. 1 and the study procedures schedule is shown in Table 1. Recruitment period will last 1.5 years, and follow-up period will be 1 year. The expected total duration of the study, from the first visit of the first patient to the last visit of the last patient, will be 2.5 years.

\section{Recruitment of eligible participants}

Patients will be recruited by the attending clinicians (vascular surgeons) among the population of chronic, type $2 \mathrm{DM}$ patients with peripheral arteriopathy that is usually under periodic follow-up in the outpatient clinic. Proposal to participate in the clinical trial will take place in one of these routine outpatient visits. Clinicians will explain to each subject the nature of the study, its purposes, procedures, expected duration, and the potential risks and benefits related to participation in the trial, as well as any inconvenience that this may entail. Patients will have enough time to read and understand the explanations before dating and signing the informed consent and will receive a copy of the signed document. Eligible patients will be (1) those aged between 40 and 90 years; (2) with type $2 \mathrm{DM}$ diagnosed for more than one year; (3) with severe vascular arteriosclerosis, defined as Rutherford-Becker (RB) category 4 and 5 [23], mono or bilateral; and (4) with impossibility of surgical or endovascular revascularization or failure of revascularization surgery performed, at least 30 days before inclusion in the study. Patients with CLI and tissue loss in the target limb (RB category 6) or previous major amputation in the target limb will be excluded from the trial. Detailed 


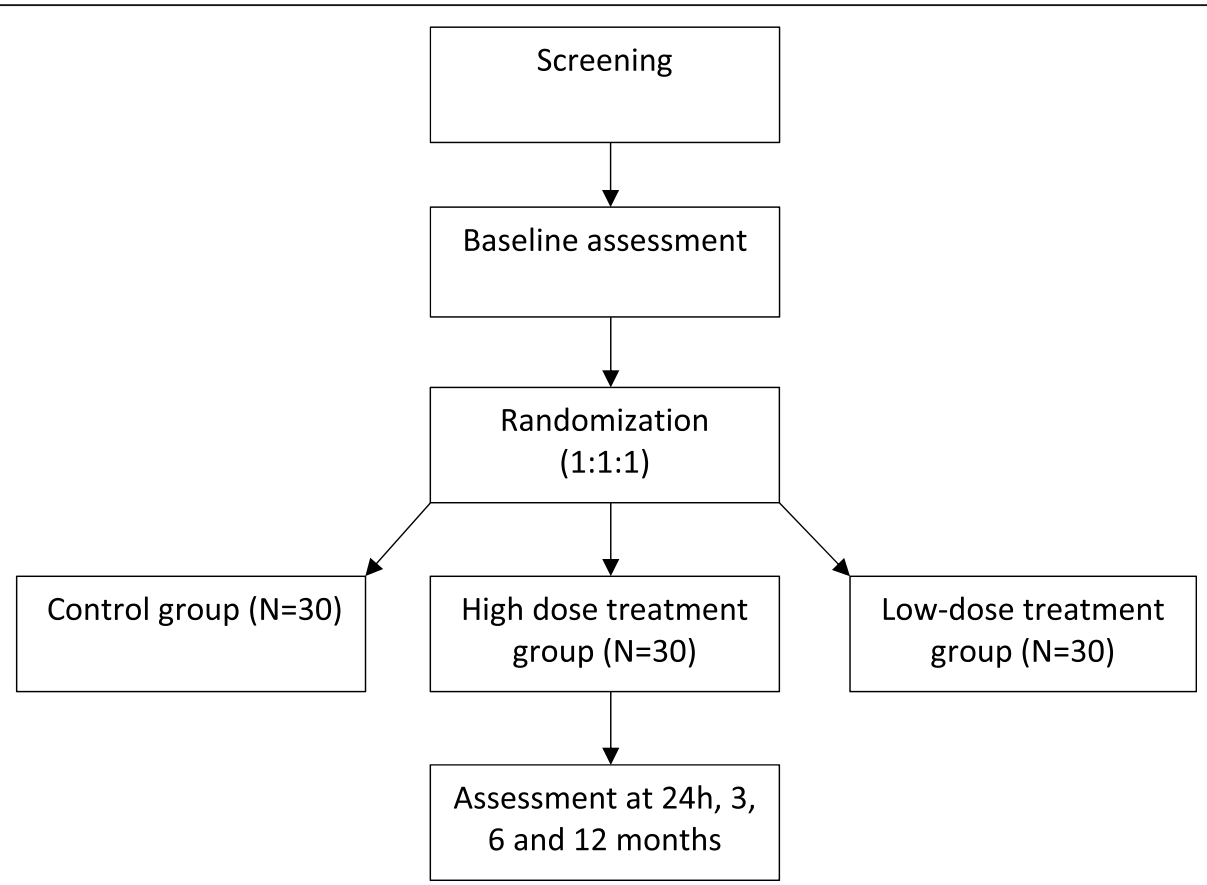

Fig. 1 Flowchart: 90 patients will be recruited in the study and randomly allocated to three groups (high-dose group = 30; low-dose group = 30; control group $=30$ ). The assessment will be done $24 \mathrm{~h}$ and 3, 6, and 12 months, respectively

eligibility criteria are described in ClinicalTrials.gov (NCT04466007). During trial conduct, periodic contacts with investigators and a trial newsletter are foreseen to assess possible difficulties in recruitment in advance and to keep investigator team informed of recruitment evolution. No specific methods to minimize attrition are foreseen. Eligible patients are severely ill patients that are usually adherent to medical visits, and thus a high drop-out rate is not expected.

\section{Blinding, randomization and allocation concealment} Masking of participants will be guaranteed as follows: the solution for intramuscular infusion of Ad-MSC (active treatment) will have the same aspect as HypoThermosolFRS (placebo), and the syringes will be identified by a label that will exclusively contain the information corresponding to the clinical trial and the patient code. However, since the density of each product may be different, it is assumed that there is a risk that the clinical investigator administering the treatment may know which treatment is being applied. For that reason and to ensure double blind, each center will count, as a minimum, with two investigators per enrolled patient: a nonblinded investigator who will administrate cellular therapy and a blinded investigator who will perform the assessment of participants as described in Table 1 . Randomization will be performed through the electronic case report form (eCRF). Study subjects will be assigned to group 1,2 , or 3 , at a ratio $1: 1: 1$, based in a random block sequence prepared by the sponsor's statistical service. The assigned group information from each participant will not be visible in the eCRF. Then, an email with the assigned treatment group information of the participant will be sent automatically to non-blinded team. No stratification process has been designed in the randomization scheme. If a phase III clinical trial is subsequently developed, stratification will be defined, according to preidentified factors that could influence efficacy outcomes. During the study, masking can be broken in the event of a serious adverse event (SAE) related to the study medication that requires urgent medical treatment. The researcher will notify the sponsor within a maximum period of $24 \mathrm{~h}$ and sign the SAE notification form that will be sent by fax or email to the person in charge of pharmacovigilance of the study. The sponsor will communicate to the investigators any information that may affect the safety of the trial subjects as soon as possible. In the event of unmasking, blinding will be maintained for those responsible for evaluating the primary variable and for those responsible for data analysis and interpretation of the results.

\section{Interventions}

Ad-MSC will be obtained from young healthy donors who previously gave their informed consent. Good manufacture practice (GMP)-accredited cell therapy laboratories from University of Navarra Clinic and from Salamanca University Hospital will be responsible of the 
Table 1 Schedule of study procedures

\begin{tabular}{|c|c|c|c|c|c|c|c|}
\hline \multirow{4}{*}{ Timepoint } & \multicolumn{7}{|l|}{ Study period } \\
\hline & \multicolumn{2}{|l|}{ Enrolment } & \multirow{2}{*}{$\begin{array}{l}\text { Treatment } \\
\text { V1, } \\
\text { treatment }\end{array}$} & \multicolumn{4}{|c|}{ Follow-up } \\
\hline & V-1, selection visit & $\begin{array}{l}\text { Vo, baseline } \\
\text { visit }\end{array}$ & & $\begin{array}{l}\text { V2, } 24 \\
h\end{array}$ & $V 3,3 \mathrm{~m}$ & $V 4,6 m$ & $V 5,12 \mathrm{~m}$ \\
\hline & $\begin{array}{l}\text { Day - } 30 \text { to day - } \\
21\end{array}$ & $\begin{array}{l}\text { Day - } 20 \text { to - } \\
1\end{array}$ & Day 0 & Day 1 & $\begin{array}{l}\text { Day }+90 \pm \\
7\end{array}$ & $\begin{array}{l}\text { Day }+180 \pm \\
15\end{array}$ & $\begin{array}{l}\text { Day }+365 \pm \\
15\end{array}$ \\
\hline Eligibility criteria & $x$ & $x$ & & & & & \\
\hline Informed consent & $x$ & & & & & & \\
\hline Anamnesis & $x$ & & & & & & \\
\hline Physical examination & $x$ & & $x$ & $x$ & $x$ & $x$ & $x$ \\
\hline Blood test & $x$ & & & & $x$ & $x$ & $x$ \\
\hline Urine pregnancy test & $x$ & & & & & & \\
\hline Rutherford-Becker category & $x$ & & & & & & \\
\hline Ankle-arm index & $x$ & & & & $x$ & $x$ & $x$ \\
\hline Ulcers evaluation (Wifi classification) & $x$ & & & & $x$ & $x$ & $x$ \\
\hline VAS scale & $x$ & & & $x$ & $x$ & $x$ & $x$ \\
\hline Gastrocnemius muscle perimeter & $x$ & & & & $x$ & $x$ & $x$ \\
\hline Temperature of the limb & $x$ & & & & $x$ & $x$ & $x$ \\
\hline Neuropathic symptoms & $x$ & & & & $x$ & $x$ & $x$ \\
\hline $\begin{array}{l}\text { Quality of life scales (SF-12 and } \\
\text { VascuQol-6) }\end{array}$ & $x$ & & & & $x$ & X & X \\
\hline MRI & $x$ & & & & & & $x$ \\
\hline Randomization & & $x$ & & & & & \\
\hline Pre surgical evaluation & & $x$ & & & & & \\
\hline Treatment administration & & & $x$ & & & & \\
\hline Concomitant medication & $x$ & $x$ & $x$ & & $x$ & $x$ & $x$ \\
\hline Adverse events & & & X & $x$ & $x$ & $x$ & $x$ \\
\hline
\end{tabular}

MRI magnetic resonance imaging, $h$ hours, $m$ month, $v$ visit

master cell bank (MCB). MCB is the system whereby successive batches of the cell therapy product are manufactured by isolation and expansion of cells derived from a single adipose tissue sample. In this way, we ensure stability and uniformity in the treatment. MCB laboratories will send batches of cryopreserved cells to working GMP cell bank (WCB) laboratories. When a participant of the study is assigned to active treatment group, the sponsor will notify the assigned WCB laboratory to thaw and culture the cells in one passage. Finally, the batch will be packaged, labeled, and sent to the pharmacy service of the corresponding hospital (see Figs. 2 and 3). Three parallel groups have been designated as follows:

- Group 1. Control group $(n=30)$. Placebo will consist of HypoThermosolFRS contained in an identical vial to that of the investigational medicinal product (IMP) and with the same volume.

- Group 2. Low-cell dose treatment group $(n=30)$. This group will receive a single intramuscular administration of $1 \times 10^{6}$ cells/Kg weight.
- Group 3. High-cell dose treatment group $(n=30)$. This group will receive a single intramuscular administration of $2 \times 10^{6}$ cells $/ \mathrm{Kg}$ weight.

Regarding the allogeneic treatment presented in this protocol and possible risk of immune rejection, MSC are considered to have an immunoprivileged status. These cells display a low expression of MHC-HLA class I and are constitutively negative for HLA class II [28], thus avoiding the presentation of antigens to cytolytic T lymphocytes and immunological rejection. Furthermore, an autologous use would entail MSC isolation from multipathological patients. It has been suggested that the hyperglycemic environment and metabolic disorders associated with diabetes affect the biological properties and angiogenic capacity of cells [29-31]. Ad-MSC isolated from young healthy donors are more likely to present uniform cellular properties [7]. Treatment will be administered intramuscularly at the infrapopliteal level, at 25 points in the ischemic area parallel to the vascularization of the affected limb (Fig. 4). Treatment 


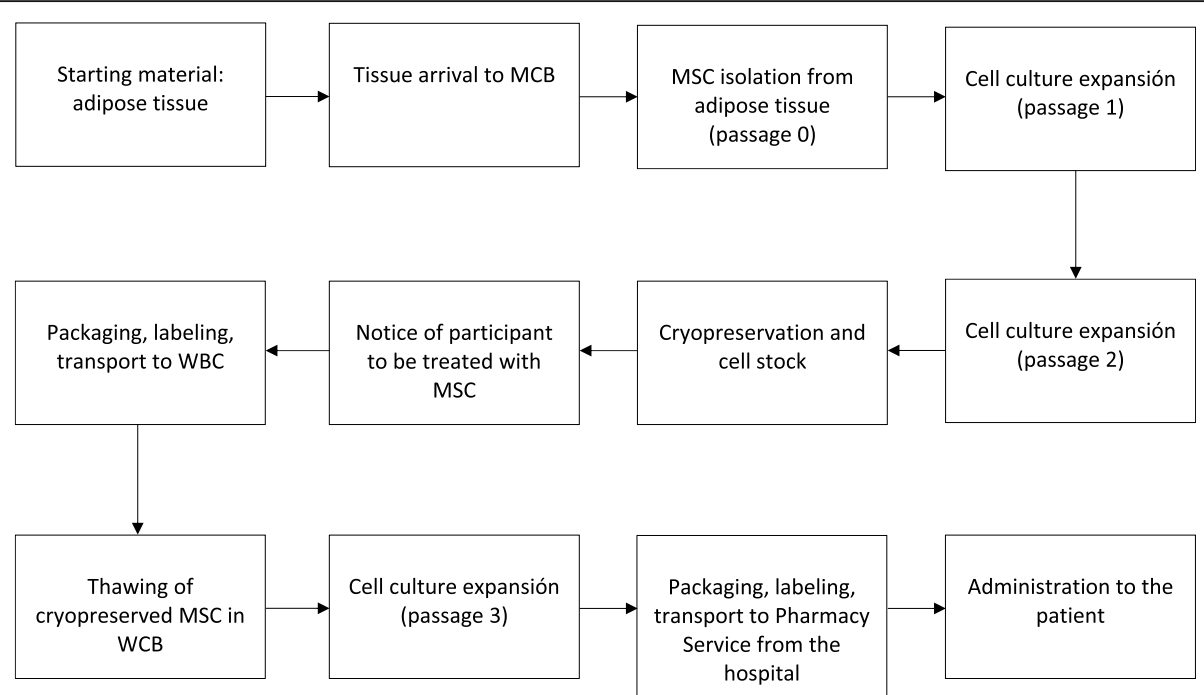

Fig. 2 Cell therapy product flowchart. From GMP laboratory to the patient. MCB, master cell bank; WCB, working cell bank; MSC, mesenchymal stromal cells. Ad-MSC are isolated from the adipose tissue sample and cultured at two passages until reaching a minimum dose of $250 \times 10^{6}$ cells. Characterization of the cells and quality controls are established during the whole process. When a study subject is assigned to active treatment group, the sponsor notifies the assigned WCB laboratory to thaw and culture the cells in one passage. The batch is then packaged, labeled, and sent to the pharmacy service of the intended hospital. Manufacture process has been authorized by the Spanish competent authority (AEMPS), PEl number 15-103 Version 4:7/07/2019.

administration will be performed in the operating room, after patients have gone through mandatory presurgical assessment. As the IMP consists of a living drug, the importance of standardizing handling of Ad-MSCs was emphasized during the design of the clinical trial. Hence, a protocol for the management and administration of the medication was established. Doses are proposed according to previous experience of the group and bibliographical data. In previous trials (Phase I/IIa), $1 \times 10^{6}$ cells $/ \mathrm{kg}$ of patient weight have been used [7, 22, 32]. In parallel and considering the results of these tests, as well as the safety demonstrated in the administration of Ad-MSC, it seems justified to check whether a higher cell dose could improve the results obtained to date. In case of bilateral affection, the limb to be treated will be the more damaged one. In addition to the IMP administration and study procedures, patients will be managed according to routine clinical practice. Patients may voluntarily discontinue the study and will be withdrawn from the study if they present any clinically relevant condition that may represent a risk. After the end of the trial, patients will be managed according to best clinical practice.

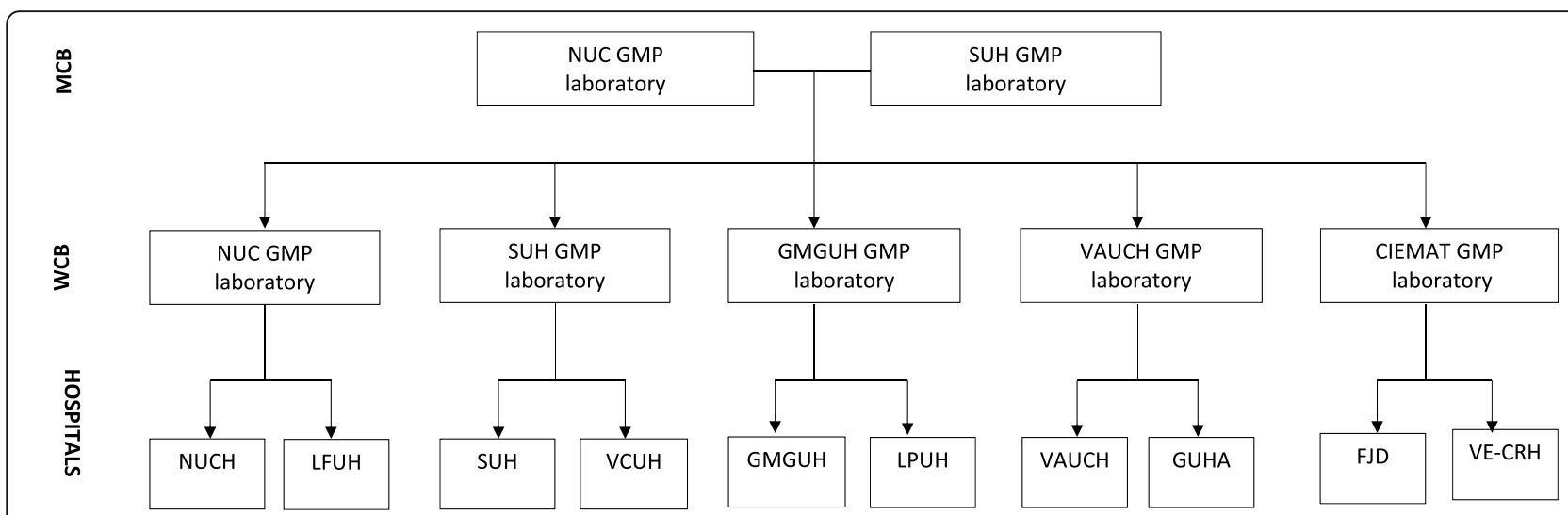

Fig. 3 MCB and WCB laboratories. Different laboratories have been assigned to the hospitals. MCB, master cell bank; WCB, working cell bank; NUC, Navarra University Hospital; SUH, Salamanca University Hospital; GMGUH, Gregorio Marañon General University Hospital; VAUCH, Virgen de la Arrixaca University Clinical Hospital; LFUH, La Fe University Hospital; VCUH, Valladolid Clinical University Hospital; LPUH, La Paz University Hospital; VE-CRH, Queen Victoria Eugenia-Cruz Roja Hospital; FJD, Jimenez Diaz Foundation University Hospital; HGUA, General University Hospital Alicante 


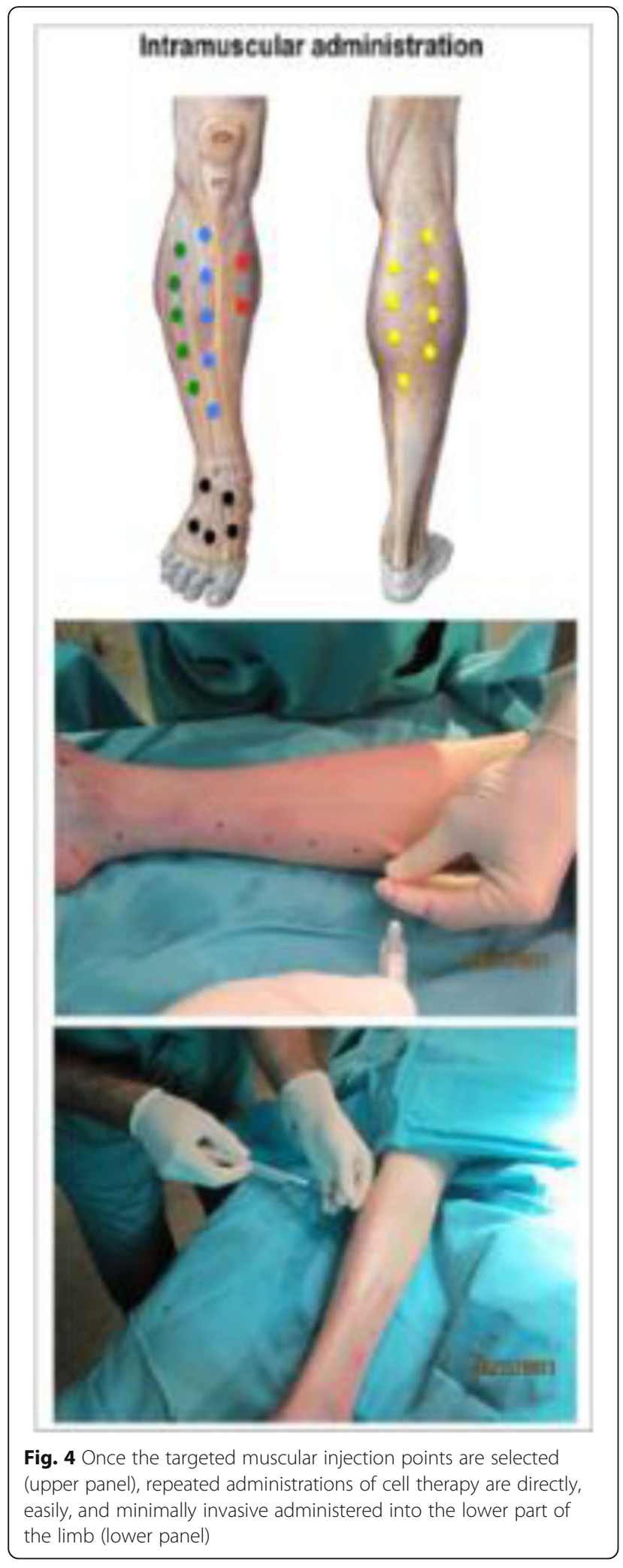

Tertiary outcome measures

Quality of life will be assessed through mean improvement scores obtained from the generic short-form-12 (SF-12) questionnaire [37] and peripheral arterial disease specific Vascular Quality of Life Questionnaire-6

\section{Outcome measures}

\section{Primary outcome measure}

Safety will be assessed comparing the rate of treatment related complications between groups (proportion of treatment related complications among groups) at $24 \mathrm{~h}$ and 3,6 , and 12 months from treatment administration, including those related with anesthetic procedure, IMP administration and those occurring after the procedure.

\section{Secondary outcome measures}

Efficacy will be assessed through the following variables:

(a) Vascularity in the target limb will be assessed through mean change in percentage of vascular flow measured by MRI in the target limb at 12 months from baseline between groups. MRI will be centrally read by a blinded radiologist. (b) Disease severity will be evaluated through percentage of patients with an improvement in RB category at 3, 6, and 12 months from baseline [33] between groups. This scale is usually used in patients with chronic arterial disease to classify chronic arterial disease into clinical categories (category 0, asymptomatic; category 1, mild claudication; category 2 , moderate claudication; category 3, severe claudication; category 4, pain at rest; category 5, minor tissue loss; category 6, ulcer o gangrene). (c) Ulcer healing (if any) will be assessed through the percentage of patients with a decrease in SVS-"WIfI" wound classification [34, 35] at 3, 6 , and 12 months from baseline between groups. SVSWIfI classification aims to be as functional in diagnosing PAD as the tumor-node-metastasis-based diagnosis system (TNM). Three measurable parameters are collected: wound (extension and depth), ischemia (blood flow), and foot infection (presence and extension). (d) PAD evolution will be evaluated by $\%$ of patients with an increase in ankle-brachial index at 3, 6, and 12 months from baseline between groups [36]. (e) Pain intensity will be assessed through mean change in visual analogue scale (VAS) from 0 to $10 \mathrm{~cm}$, as described by the patient ( 0 , absence of pain; $1-3$, mild; $4-7$, moderate; $8-10$, severe) and percentage of patients with an improvement in pain intensity at rest at 3,6 , and 12 months from baseline between groups. (f) Percentage of patients with a decrease in temperature $\left({ }^{\circ} \mathrm{C}\right)$, increase in gastrocnemius muscle perimeter $(\mathrm{cm})$ and decrease in neuropathic symptoms of the treated limb compared with contralateral at 3, 6, and 12 months from baseline. (g) Mean change in percentage of amputations in each group at the end of the study will be registered. 
(VascuQoL-6) [38] at 3, 6, and 12 months from baseline between groups. SF-12 scale is a reduced version of the SF-36 questionnaire, easy-to-apply to assess the functional capacity of people over 14 years of age. It includes the following dimensions: physical role, body pain, mental health, general health, vitality, social function, and emotional role. In this case, we will use version 2 , in which 50 (with an SD of 10) is taken as the mean of the general population. Values above 50 should be interpreted as best, while values below 50 should be interpreted as worse than the mean. For each of the items in each dimension, the score ranges from 0 (the worst health for that dimension) to 100 (the best health for that dimension). VascuQoL-6 questionnaire consists of six questions with a score of $1-4$ in each question. To obtain the general score of the questionnaire, it is necessary to add all the points obtained in each question. A high final value indicates a better state of health. As there is no validated version in Spanish, our research group is performing a cross-cultural adaptation and validation of this questionnaire in Spanish.

\section{Adverse events}

An adverse event (AE), also referred to as an adverse experience, can be any unfavorable and unintended sign (i.e., an abnormal laboratory finding), symptom, or disease temporally associated with the use of a drug (or other investigational therapy) and does not imply any judgment about causality. An AE can arise with any use of the drug (i.e., off-label use, use in combination with another drug and with any route of administration, formulation, or dose, including an overdose). A suspected adverse reaction (SAR) means any AR for which there is a reasonable possibility that the drug caused the AE. An $\mathrm{AE}$ is considered "serious" if (SAE), in the view of either the principal investigator, if it results in any of the following outcomes: death of subject; event with risk to life, that is, there was an immediate risk of subject death at the time the reaction was observed; hospitalization or prolongation of hospitalization; persistent or significant disability/incapacity; congenital anomaly; or birth defect or any other significant medical condition, i.e., important AEs that do not pose an immediate risk to life and do not result in death or hospitalization but may endanger the subject or may require intervention to prevent one of the outcomes listed. A suspected adverse reaction is considered "unexpected" if it is not listed in the safety reference information for the IMP or is not listed at the specificity or severity that has been observed or is not consistent with previously available, known risk information.

Causality and severity assessment of any occurring $\mathrm{AE}$ will be performed by the principal investigator. AE will be registered from administration of IMP to end of study visit. Investigator will actively ask patients about $\mathrm{AE}$ occurrence in every study visit. Also, AE may be spontaneously reported by the patients. All of them will be appropriately registered in the patient medical records. Only AR and SAE will be registered in eCRF and reported according to legal requirements. For the purposes of this study, proportion of amputations in each study group is a secondary outcome and will be registered specifically, so notification as SAE will not be performed unless its clinical course is different of more severe than expected.

\section{Statistical considerations Sample size calculation}

A formal size calculation based on the expected differences for the primary outcome has not been performed. This is a phase II, dose-finding study, and no previous data on the preliminary efficacy of Ad-MSC with CLI including type $2 \mathrm{DM}$ patients are available to date. A sample size of 30 patients per group was deemed appropriated based on the possibility to reach normality and the feasibility to recruit 90 eligible patients in 10 university hospitals.

\section{Data collection and management}

Relevant information for the study will be registered in electronic medical records and then entered in the eCRF in a pseudonymized fashion. All of these data will be also documented in the investigator's file, which will be saved in key-locked cabinets. Monitor may need to verify the original data against the subject's medical history and sponsor will have access to the final trial dataset.

\section{Statistical analysis}

Primary, secondary, and tertiary outcomes (safety, efficacy, and quality of life) will be assessed in intention to treat (ITT) and per protocol (PP) populations [39]. ITT population will include all patients who sign the informed consent and receive the investigational product. PP population will include patients who complete the 12-month follow-up period. A descriptive analysis of baseline characteristics of patients included in three groups will be performed. Quantitative variables will be expressed as mean and/or median and standard deviation and/or range. Qualitative variables will be expressed as percentages. When possible, the $95 \%$ confidence interval of each of the estimates made will be calculated. To analyze the primary outcomes, $24 \mathrm{~h}$ and 3,6 , and 12 months complication rates will be described and compared for the three groups using the Chi-square test or, if necessary, the Fisher exact test. The analyses of the secondary and tertiary outcomes will be performed as follows: qualitative variables will be described in terms of the percentage of improvement of the medical 
condition in each group and compared using the Chisquare test, or alternatively Fisher's exact test. VAS scale, SF-12 scale, VascuQuol-6 scale, and the rest of the quantitative variables will be assessed by describing changes in variables at 3,6 , and 12 months from baseline, in an absolute and relative way. Changes at 3, 6 , and 12 months in the three groups will be described and compared using the analysis of variance test, or the Kruskal-Wallis test, depending on whether or not the data follow a normal distribution. In all comparisons, a global comparison of the three groups and comparisons between groups by pairing will be carried out (low-dose treatment versus placebo, high-dose treatment versus placebo, high-dose treatment versus low dose, both treatment groups versus placebo). $\mathrm{P}$ values will be corrected by Bonferroni test. Regarding handling of missing data, a complete case analysis will be performed if percent of missing data is less than $5 \%$. In another case, a data imputation will be performed for those variables with $25 \%$ or less missing values. Variables with more than $25 \%$ missing values will be removed from the analysis. The statistical analysis will be carried out by the statistical service of the Jiménez Díaz Foundation University Hospital. Data analyst will be blinded.

So far, no plans to use data generated in this trial for additional studies is foreseen. Nevertheless, and according to GDPR requirements, a statement has been included in the informed consent form informing the patient about this possibility and asking her/him for permission.

\section{Auditing}

The study is supported by SCReN (Spanish Clinical Research Network) funded by ISCIII-General Subdivision for Evaluation and Promotion of Research, project PT17/0017/0022-PT20-00142 integrated in the 20132016 NationalI+D+iPlan, and co-financed by the European Regional Development Fund (FEDER). SCReN will be in charge of project management, monitoring, and pharmacovigilance activities.

\section{Discussion}

Patients with type 2 DM tend to develop more advanced forms of CLI [40], displaying a combination of macro and microangiopathy, neuropathy with loss of sensation, tissue damage, increased risk of infection, endothelial inflammation, pro-thrombosis, and a greater inflammatory response, leading to a more distal, diffuse, and severe disease [41]. Currently, 6000 amputations are performed yearly in our country, and more than $70-80 \%$ are due to PAD. Despite its dramatic social impact, treatment options are limited due to the very negative long-term prognosis, with an increase in mortality after 10 years, 15 times higher than the patients without PAD [42].
Regenerative medicine is making possible to address unmet therapeutic needs. Specifically, cell-based therapy is positioning itself as one of the most promising approaches, generating great progress and a new frontier in healthcare. Cell therapy programs have opened on a wide range of fields with translational goals, providing sufficient evidence to show that it is a safe treatment [25-27, 43, 44]. Efficacy of the intramuscular administration of autologous Ad-MSC in type 2 DM patients with CLI was demonstrated in the pilot study conducted by Riera et al., showing a statistically significant improvement in health-related quality of life, an increase in $\mathrm{ABI}$, and a decrease in $\mathrm{RB}$ category in the posttreatment period [32]. To our knowledge, no randomized clinical trial protocols consisting of the administration of Ad-MSC in type 2 DM patients with CLI have been published to date. Given that current treatment is not established in daily clinical practice, it is essential to promote and systematize the knowledge already obtained with the aim of developing well-designed cell therapy-based clinical trials. In our previous experience, management of the IMP to ensure the viability and survival of MSC is essential and was discussed in multiple meetings, leading to the development of a protocol for the correct handling and administration of the cell-based therapy. The implementation of this protocol implies a great coordination effort, in which basic and clinical researchers worked together to ensure that the living medicinal product reaches from the laboratory to the patient. Finally, the design of a multicenter independentdriven clinical trial based on cell therapy administration represents a challenge requiring a large logistical organization (as shown in Figs. 2 and 3) and great involvement and collaboration from the entire research team for the study to be feasible. "Feasibility" of the NOMA clinical trial also refers to the following characteristics of the proposed intervention: (i) On the one hand, it is an allogeneic product, in which 30 batches of cell therapy at a dose of $1 \times 10^{6}$ cells $/ \mathrm{kg}$ of weight, and 30 batches of cell therapy at a dose of $2 \times 10^{6}$ cells $/ \mathrm{kg}$ of body weight are obtained from a single liposuction. In autologous uses, patient needs to undergo liposuction in a first stage, and the administration of the cell therapy in a second stage. (ii) On the other hand, an intramuscular administration has been proposed, technically simpler than intravascular administration. Hence, an easy-toapply cell therapy is proposed in this protocol, contributing to the feasibility of the intervention in a clinical setting. This will undoubtfully be useful to conduct academic clinical trials in the field of cell therapy in the near future.

\section{Abbreviations}

ABI: Ankle-brachial index; Ad-MSC: Adipose tissue-derived mesenchymal stromal cells; ATMP: Advanced therapy medicinal product; BM: Bone marrow; 
CLI: Critical limb ischemia; EC: Ethics committee; eCRF: Electronic case report form; GMP: Good manufacture practice; IMP: Investigational medicinal product; ITT: Intention to treat; MCB: Master cell bank; MSC: Mesenchymal stromal cells; MRI: Magnetic resonance imaging; NOMA: No more amputations; PAD: Peripheral arterial disease; PP: Per protocol; RB: Rutherford-Becker; SAE: Serious adverse event; SF: Short form; SVSWIfl: Society for Vascular Surgery-Wound Ischemia and Foot Infection Classification System; TACT study: Therapeutic Angiogenesis using Cell Transplantation study; Type 2 DM: Type 2 diabetes mellitus; TNM: Tumornode-metastasis-based classification system; VAS: Visual analogue scale; VascuQoL: Vascular Quality of Life Questionnaire; WCB: Working cell bank

\section{Acknowledgements}

The authors acknowledge Project Manager and Clinical Research Associate Ms. Mireia Arcas and CTA Support from Ms. Gloria Aranaz and Ms. Iris Moreno.

\section{Contact information of trial sponsor}

Foundation Jiménez Díaz Foundation Health Research Institute, Avda, Reyes católicos 8, 28040, Madrid, Spain. Project Manager: Mireia Arcas, mireia. arcas@fjd.es

\section{Trial status}

The version number of this protocol is 2.0, dated on April 24, 2020. Recruitment began on December 15, 2020, and is expected to be completed by the end of 2022 .

\section{Authors' contributions}

$B S, A H, M G A$, and DGO conceived the trial. BS-J wrote the first draft that was revised by $B S, A H, L L, M G A$, and DGO. All authors revised and approved the final version of the manuscript for submission.

\section{Funding}

This is an academic clinical trial that has been funded by the competitive, public call for Independent Clinical Research Projects in Advanced Therapies within the framework of the Strategic Action in Health of the year 2017 (BOE 11/21/2017) of the Carlos III Health Institute (file number PIC 18/00010). The economic endowment for the development of the project has been transferred from the Carlos III Health Institute to the Health Research Institute of the Jiménez Díaz Foundation University Hospital (IIS-FJD), which acts as a sponsor of the project and whose legal representative is the Manager of the Jiménez Díaz Foundation University Hospital. Neither the funding source nor the sponsor have been involved in any part of the design or writing of the manuscript and will not be involved in its execution, data analysis, or decision to submit results. As an academic-driven clinical trial, coordinating investigators and their research team, on behalf of the sponsor, will be in charge of the adequate conduct of the trial, data analysis and interpretation, writing the report, and for submission of the report for publication and will have the ultimate authority over all of these activities. The general management of the trial will be in charge of the FJD Clinical Research Unit, which will be the leading Research Unit for the Project. FJD Health Research Institute Clinical Research Unit (FJD CRU) belongs to the Spanish Clinical Research Network, a publicly funded network which depends on the Carlos III Health Institute and provides methodological, regulatory, monitoring, and pharmacovigilance support, among others. Regulatory activities, monitoring, pharmacovigilance, and eCRD design and hiring will be performed by adequately trained staff from the Spanish Clinical Research Network (SCREN). IIS-FJD will assume overall responsibility for the initiation and management of the project and ensuring compliance with the relevant legal regulations. The sponsor and research team have the intellectual property rights. There is no company that produces IMPD. Cell therapy is manufactured in authorized and accredited laboratories of the Spanish national health system, institutions with state funding within the national network of cell therapy (TerCel) funded by the ISCIII.

\section{Availability of data and materials}

The full trial protocol and amendment history, and the anonymized participant-level dataset, will be made publicly available as supplementary material with the study results publication and in ClinicalTrials.gov and Spanish clinical trials (ReEC) registers after clinical study report has been sent to the National Competent Authority.

\section{Declarations}

Ethics approval and consent to participate

This trial has been approved by FJD Ethics Committee (EC) and National Competent Authority (AEMPS) and will be performed in accordance with the Declaration of Helsinki. Written, informed consent to participate will be obtained from all participants. All information collected will be treated strictly confidential, in accordance with current regulations: Organic Law 3/2018 of December 5, Protection of Personal Data and Guarantee of Digital Rights, Regulation (EU) 2016/679 of the European Parliament and of the Council, of April 27, 2016 (GDPR), General Health Law 14/1986 and Law 14/2007 of Biomedical Research, Law 41/2002 of Patient Autonomy. Since it is a clinical trial that uses a not marketed investigational advanced therapy medicinal product, the sponsor of the study has contracted a civil liability insurance policy to cover compensation for potential harms suffered from trial participation. Relevant protocol amendments will be communicated to the investigators after EC and AEMPS approval. The sponsor agrees to publish the study results, either positive or negative, of the clinical trial, preferably in open-access scientific journals before being disclosed to the non-health public. Authorship will be considered following ICMJE guidelines. The rest of personnel involved in the clinical trial but not meeting authorship criteria will be acknowledged in the Contribution section. No hiring of professional writers has been performed to write this manuscript and will not be in the writing of the final study report for publication.

\section{Consent for publication}

Not applicable

\section{Competing interests}

The authors declare that they have no competing interests.

\section{Author details}

${ }^{1}$ Jimenez Diaz Foundation University Hospital, FJD Health Research Institute, IIS-FJD UAM, Madrid, Spain. ${ }^{2}$ La Paz University Hospital, Madrid, Spain. ${ }^{3}$ Navarra University Clinic, Pamplona, Navarra, Spain. ${ }^{4}$ Virgen de la Arrixaca University Hospital, Murcia, Spain. ${ }^{5}$ BSAL-University Hospital of Salamanca, University of Salamanca, Salamanca, Spain. ${ }^{6}$ Hematopoietic Innovative Therapies Division, Centro de Investigaciones Energéticas, Medioambientales y Tecnológicas (CIEMAT), Madrid, Spain. ${ }^{7}$ Queen Victoria Eugenia-Cruz Roja Hospital, Sevilla, Spain. ${ }^{8}$ University of Pablo de Olavide, Sevilla, Spain.

${ }^{9}$ Network Center for Research in Diabetes and Associated Metabolic Diseases (Centro de Investigación Biomédica en Red de Diabetes y Enfermedades Metabólicas Asociadas_CIBERDEM), Instituto de Salud Carlos III, Madrid, Spain. ${ }^{10}$ La Fe University Hospital, Valencia, Spain. ${ }^{11}$ Valladolid Clinical University Hospital, Valladolid, Spain. ${ }^{12}$ Institute for Health Research Gregorio Marañón (IISGM), General University Gregorio Marañón Hospital, Madrid, Spain. ${ }^{13}$ Institute for Health Research-ISABIAL, General University Hospital, Alicante, Spain. ${ }^{14}$ University Miguel Hernández de Elche, Alicante, Spain.

${ }^{15}$ The Spanish Biomedical Research Centre in Diabetes and Associated Metabolic Disorders (CIBERDEM), Madrid, Spain. ${ }^{16}$ University of Alicante, Alicante, Spain.

Received: 11 March 2021 Accepted: 7 July 2021

Published online: 06 September 2021

\section{References}

1. Dormandy JA, Rutherford RB. Management of peripheral arterial disease (PAD). TASC Working Group. Trans Atlantic Inter-Society Consensus (TASC). J Vasc Surg. 2000;31(1 Pt 2):S1-S1-296.

2. Albright RH, Manohar NB, Murillo JF, Kengne LAM, Delgado-Hurtado JJ, Diamond ML, et al. Effectiveness of multidisciplinary care teams in reducing major amputation rate in adults with diabetes: a systematic review \& metaanalysis. Diabetes Res Clin Pract. 2020;161:107996. https://doi.org/10.1016/j. diabres.2019.107996.

3. Nativel $M$, Potier $L$, Alexandre $L$, et al. Lower extremity arterial disease in patients with diabetes: a contemporary narrative review. Cardiovasc Diabetol. 2018;17(1):138. https://doi.org/10.1186/s12933-018-0781-1. 
4. Saha SP, Whayne TF Jr, Mukherjee D. Current evidence for antithrombotic therapy after peripheral vascular interventions. Curr Vasc Pharmacol. 2013; 11(4):507-13. https://doi.org/10.2174/1570161111311040014.

5. Isner JM, Rosenfield K. Redefining the treatment of peripheral artery disease. Role of percutaneous revascularization. Circulation. 1993;88(4 Pt 1):1534-57.

6. Ramsey SD, Newton K, Blough D, McCulloch DK, Sandhu N, Wagner EH. Patient-level estimates of the cost of complications in diabetes in a managed-care population. PharmacoEconomics. 1999;16(3):285-95.

7. Soria-Juan B, Soria-Juan B, Escacena N, Capilla-González V, Aguilera Y, Llanos $L$, et al. Cost-effective, safe, and personalized cell therapy for critical limb ischemia in type 2 diabetes mellitus. Front Immunol. 2019;10:1151. https:// doi.org/10.3389/fimmu.2019.01151 eCollection 2019.

8. Isner JM, Pieczek A, Schainfeld R, et al. Clinical evidence of angiogenesis after arterial gene transfer of phVEGF165 in patient with ischaemic limb. Lancet. 1996;348(9024):370-4. https://doi.org/10.1016/s0140-6736(96)033 61-2.

9. Baumgartner I, Pieczek A, Manor O, Blair R, Kearney M, Walsh K, et al. Constitutive expression of phVEGF165 after intramuscular gene transfer promotes collateral vessel development in patients with critical limb ischemia. Circulation. 1998;97(12):1114-23. https://doi.org/10.1161/01.cir. 97.12.1114.

10. Kusumanto YH, Weel V, Mulder NH, Smit AJ, Dungen JJ, Hooymans AM, et al. Treatment with intra muscular (IM) vascular endothelial growth factor (VEGF) gene compared with placebo for patients with diabetes mellitus and critical limb ischemia (CLI), a double blind randomized trial. Hum Gene Ther. 2006;17(6):683-91. https://doi.org/10.1089/hum.2006.17.683.

11. Comerota AJ, Throm RC, Miller KA, Henry T, Chronos N, Laird J, et al. Naked plasmid DNA encoding fibroblast growth factor type 1 for the treatment of end-stage unreconstructible lower extremity ischemia: preliminary results of a phase I trial. J Vasc Surg. 2002;35(5):930 -930-6.

12. Isner JM, Walsh K, Symes J, Pieczek A, Takeshita S, Lowry J, et al. Arterial gene transfer for therapeutic angiogenesis in patients with peripheral artery disease. Hum Gene Ther. 1996;7(8):959-88.

13. Ho HK, Jang JJ, Kaji S, Spektor G, Fong A, Yang P, et al. Developmental endothelial locus-1 (Del-1), a novel angiogenic protein: its role in ischemia. Circulation. 2004;109(10):1314 -1314-9.

14. Rajagopalan S, Mohler ER 3rd, Lederman RJ, Mendelsohn FO, Saucedo JF, Goldman CK, et al. Regional angiogenesis with vascular endothelial growth factor in peripheral arterial disease: a phase II randomized, double-blind, controlled study of adenoviral delivery of vascular endothelial growth factor 121 in patients with disabling intermittent claudication. Circulation. 2003; 108(16):1933-1933-8.

15. Creager MA, Olin JW, Belch JJF, Moneta GL, Henry TD, Rajagopalan S, et al. Effect of hypoxia-inducible factor-1alpha gene therapy on walking performance in patients with intermittent claudication. Circulation. 2011 124(16):1765-73.

16. Nikol S, Baumgartner I, Van Belle E, Diehm C, Visoná A, Capogrossi MC, et al. Therapeutic angiogenesis with intramuscular NV1FGF improves amputationfree survival in patients with critical limb ischemia. Mol Ther. 2008;16(5):9728. https://doi.org/10.1038/mt.2008.33.

17. Asahara T, Murohara T, Sullivan A, Silver M, van der Zee R, Li T, et al. Isolation of putative progenitor endothelial cells for angiogenesis. Science. 1997;275(5302):964-7.

18. Freedman SB, Isner JM. Therapeutic angiogenesis for coronary artery disease. Ann Intern Med. 2002;136(1):54-71. https://doi.org/10.7326/0003-4 819-136-1-200201010-00011.

19. Novakova V, Sandhu GS, Dragomir-Daescu D, Klabusay M. Apelinergic system in endothelial cells and its role in angiogenesis in myocardial ischemia. Vascul Pharmacol. 2016;76:1-10.

20. Van Raemdonck K, Van den Steen PE, Liekens S, Van Damme J, Struyf S. CXCR3 ligands in disease and therapy. Cytokine Growth Factor Rev. 2015; 26(3):311-27.

21. Leeper NJ, Hunter AL, Cooke JP. Stem cell therapy for vascular regeneration: adult, embryonic, and induced pluripotent stem cells. Circulation. 2010; 122(5):517-26

22. Tateishi-Yuyama E, Matsubara H, Murohara T, Ikeda U, Shintani S, Masaki $H$, et al. Therapeutic angiogenesis for patients with limb ischaemia by autologous transplantation of bone-marrow cells: a pilot study and a randomised controlled trial. Lancet. 2002;360(9331):42735
23. Saigawa T, Kato K, Ozawa T, Toba K, Makiyama Y, Minagawa S, et al. Clinical application of bone marrow implantation in patients with arteriosclerosis obliterans, and the association between efficacy and the number of implanted bone marrow cells. Circ J. 2004;68(12):1189-93. https://doi.org/1 0.1253/circj.68.1189.

24. Miyamoto K, Nishigami K, Nagaya N, Akutsu K, Chiku M, Kamei M, et al. Unblinded pilot study of autologous transplantation of bone marrow mononuclear cells in patients with thromboangiitis obliterans. Circulation. 2006;114(24):2679-84

25. Ruiz-Salmeron R, de la Cuesta-Diaz A, Constantino-Bermejo M, PérezCamacho I, Marcos-Sánchez F, Hmadcha A, et al. Angiographic demonstration of neoangiogenesis after intra-arterial infusion of autologous bone marrow mononuclear cells in diabetic patients with critical limb ischemia. Cell Transplant. 2011;20(10):1629-39.

26. Cañizo MC, Lozano F, González-Porras JR, Barros M, López-Holgado N, Briz E, et al. Peripheral endothelial progenitor cells $(C D 133+)$ for therapeutic vasculogenesis in a patient with critical limb ischemia. One year follow-up. Cytotherapy. 2007;9(1):99-102.

27. Abdelkrim H, Juan D-B, Jane W, Mohamed A, Bernat S. The immune boundaries for stem cell based therapies: problems and prospective solutions. J Cell Mol Med. 2009;13(8a):1464-35.

28. Le Blanc K. Immunomodulatory effects of fetal and adult mesenchymal stem cells. Cytotherapy. 2003;5:485-9. https://doi.org/10.1080/1465324031 0003611.

29. Ferrer-Lorente R, Bejar MT, Tous M, Vilahur G, Badimon L. Systems biology approach to identify alterations in the stem cell reservoir of subcutaneous adipose tissue in a rat model of diabetes: effects on differentiation potential and function. Diabetologia. 2014;57:246-56. https://doi.org/10.1007/s00125013-3081-z.

30. Minteer DM, Young MT, Lin YC, Over PJ, Rubin JP, Gerlach JC, et al. Analysis of type II diabetes mellitus adipose-derived stem cells for tissue engineering applications. J Tissue Eng. 2015;6:2041731415579215. https://doi.org/10.11 77/2041731415579215

31. Rennert RC, Sorkin M, Januszyk M, Duscher D, Kosaraju R, Chung MT, et al. Diabetes impairs the angiogenic potential of adipose-derived stem cells by selectively depleting cellular subpopulations. Stem Cell Res Ther. 2014;5:79. https://doi.org/10.1186/scrt468.

32. Riera del Moral L, Salazar Álvarez A, StefanovKiuri S, Tong H, Riera de Cubas L, García-Olmo D, et al. Phase lb open clinical trial to assess the safety of autologous mesenchymal stem cells for the treatment of non revascularizable critical lower limb ischemia. J Stem Cell Res Ther. 2017;7:6.

33. Hardman RL, Jazaeri O, Yi J, Smith M, Gupta R. Overview of classification systems in peripheral artery disease. Semin Intervent Radiol. 2014;31(4):37888. https://doi.org/10.1055/s-0034-1393976.

34. Mills JL, Society for Vascular Surgery Lower Extremity Guidelines Committee, et al. The Society for Vascular Surgery Lower Extremity Threatened Limb Classification System: risk stratification based on wound, ischemia, and foot infection (WIfI). J Vasc Surg. 2014;59(1):220-34.e1-2. https://doi.org/10.1016/j. jvs.2013.08.003.

35. Weaver ML, et al. The SVS WIfl classification system predicts wound healing better than direct angiosome perfusion in diabetic foot wounds. J Vasc Surg. 2018;68:1473-81.

36. Rac-Albu M, Iliuta L, Guberna SM, Sinescu C. The role of ankle-brachial index for predicting peripheral arterial disease. Maedica (Bucur). 2014;9(3):295-302.

37. Ware J Jr, Kosinski M, Keller SD. A 12-Item Short-Form Health Survey: construction of scales and preliminary tests of reliability and validity. Med Care. 1996;34(3):220-33.

38. Morgan MB, Crayford T, Murrin B, Fraser SC. Developing the vascular quality of life questionnaire: a new disease-specific quality of life measure for use in lower limb ischemia. J Vasc Surg. 2001;33(4):679-87. https://doi.org/10.1067/ mva.2001.112326.

39. Gupta SK. Intention-to-treat concept: a review. Perspect Clin. Res. 2011;2(3): 109-12. https://doi.org/10.4103/2229-3485.83221.

40. Gensler SW, Haimovici H, Hoffert P, Steinman C, Beneventano TC. Study of vascular lesions in diabetic, nondiabetic patients: clinical, arteriographic, and surgical considerations. Arch Surg. 1965;91(4):617-22.

41. Ciavarella A, Silletti A, Mustacchio A, Gargiulo M, Galaverni MC, Stella A, et al. Angiographic evaluation of the anatomic pattern of arterial obstructions in diabetic patients with critical limb ischaemia. Diabetes Metab. 1993:19(6):586-9. 
42. Hirsch AT, Haskal ZJ, Hertzer NR, Bakal CW, Creager MA, Halperin JL, et al. ACC/AHA 2005 Practice Guidelines for the management of patients with peripheral arterial disease (lower extremity, renal, mesenteric, and abdominal aortic): a collaborative report from the American Association for Vascular Surgery/Society for Vascular Surgery, Society for Cardiovascular Angiography and Interventions, Society for Vascular Medicine and Biology, Society of Interventional Radiology, and the ACC/AHA Task Force on Practice Guidelines (Writing Committee to Develop Guidelines for the Management of Patients With Peripheral Arterial Disease): endorsed by the American Association of Cardiovascular and Pulmonary Rehabilitation; National Heart, Lung, and Blood Institute; Society for Vascular Nursing; TransAtlantic Inter-Society Consensus; and Vascular Disease Foundation. Circulation. 2006;113(11):e463-654.

43. Escacena N, Quesada-Hernández E, Capilla-Gonzalez V, Soria B, Hmadcha A. Bottlenecks in the efficient use of advanced therapy medicinal products based on mesenchymal stromal cells. Stem Cells Int. 2015;2015:1-12.

44. Acosta L, Hmadcha A, Escacena N, Pérez-Camacho I, de la Cuesta A, RuizSalmeron R, et al. Adipose mesenchymal stromal cells isolated from type 2 diabetic patients display reduced fibrinolytic activity. Diabetes. 2013;62(12): 4266-9.

\section{Publisher's Note}

Springer Nature remains neutral with regard to jurisdictional claims in published maps and institutional affiliations.

- fast, convenient online submission

- thorough peer review by experienced researchers in your field

- rapid publication on acceptance

- support for research data, including large and complex data types

- gold Open Access which fosters wider collaboration and increased citations

- maximum visibility for your research: over $100 \mathrm{M}$ website views per year

At BMC, research is always in progress.

Learn more biomedcentral.com/submissions 